\title{
Review
}

\section{Structural Imaging and Parkinson's Disease: Moving Toward Quantitative Markers of Disease Progression}

\author{
N.W. Sterling ${ }^{\mathrm{a}}$, M.M. Lewis ${ }^{\mathrm{a}, \mathrm{b}}$, G. Du ${ }^{\mathrm{a}}$ and X. Huang ${ }^{\mathrm{a}, \mathrm{b}, \mathrm{c}, \mathrm{d}, \mathrm{e}, *}$ \\ ${ }^{a}$ Department of Neurology, Pennsylvania State University-Milton S. Hershey Medical Center, Hershey, PA, USA \\ ${ }^{\mathrm{b}}$ Department of Pharmacology, Pennsylvania State University-Milton S. Hershey Medical Center, Hershey, \\ $P A, U S A$ \\ ${ }^{\mathrm{c}}$ Department of Radiology, Pennsylvania State University-Milton S. Hershey Medical Center, Hershey, PA, USA \\ ${ }^{\mathrm{d}}$ Department of Neurosurgery, Pennsylvania State University-Milton S. Hershey Medical Center, Hershey, \\ $P A, U S A$ \\ ${ }^{\mathrm{e}}$ Department of Kinesiology, Pennsylvania State University-Milton S. Hershey Medical Center, Hershey, \\ $P A, U S A$
}

\begin{abstract}
Parkinson's disease (PD) is a progressive age-related neurodegenerative disorder. Although the pathological hallmark of PD is dopaminergic cell death in the substantia nigra pars compacta, widespread neurodegenerative changes occur throughout the brain as disease progresses. Postmortem studies, for example, have demonstrated the presence of Lewy pathology, apoptosis, and loss of neurotransmitters and interneurons in both cortical and subcortical regions of PD patients. Many in vivo structural imaging studies have attempted to gauge PD-related pathology, particularly in gray matter, with the hope of identifying an imaging biomarker. Reports of brain atrophy in PD, however, have been inconsistent, most likely due to differences in the studied populations (i.e. different disease stages and/or clinical subtypes), experimental designs (i.e. cross-sectional vs. longitudinal), and image analysis methodologies (i.e. automatic vs. manual segmentation). This review attempts to summarize the current state of gray matter structural imaging research in PD in relationship to disease progression, reconciling some of the differences in reported results, and to identify challenges and future avenues.
\end{abstract}

Keywords: Parkinson's disease, MRI, structure, review

\section{INTRODUCTION}

Parkinson's disease (PD) is an age-related neurodegenerative disorder marked clinically by resting tremor, bradykinesia, and rigidity. PD diagnosis and

\footnotetext{
*Correspondence to: Xuemei Huang M.D., Ph.D., Department of Neurology, Penn State University-Milton S. Hershey Medical Center, H037, 500 University Drive, Hershey, PA 17033-0850, USA. Tel.: +1 717531 0003/Ext. 287082; Fax: +1 717531 0266; E-mail: xuemei@psu.edu.
}

treatment are based primarily upon clinical symptoms and physical examination. Currently, however, there are no objective biomarkers that can diagnose PD or gauge disease severity. Thus, there is a need for markers of PD and its progression that can identify and follow different clinical trajectories that may help design treatment strategies $[1,2]$.

There is an urgent need to identify and/or develop neuroprotective agents that can slow or reverse the trajectory of PD-related neurodegeneration. 
The majority of trials investigating neuroprotective agents utilize clinical criteria (i.e. motor scores and time to levodopa initiation) as endpoints [3]. Such clinical measurements are known to have poor interrater reliability and are subject to rater bias $[4,5]$. In contrast, structural imaging has the potential to provide objective in vivo measurements of neurodegeneration. In addition to facilitating the development and evaluation of new treatment strategies, imaging measurements of $\mathrm{PD}$ and its progression may provide insights regarding fundamental pathologic processes in PD, leading to a better scientific understanding of the disease process.

Overall, reports of gray matter volume and morphometric changes in PD have been inconsistent and the locations of changes have been extremely variable. This might suggest that structural imaging has little diagnostic utility at the individual patient level, but another interpretation is that structural methodologies have been crude in the past, necessitating further technical advancement to be useful clinically. It is important to note that there have been remarkable differences in the methods used for extracting brain volume and morphometric data across studies. These techniques may be classified roughly into regions-of-interest (ROIs) based approaches (i.e. manual labeling, automatic, or semi-automatic segmentation), voxel-based whole-brain morphometric analysis [i.e. voxel-based morphometry (VBM) or tensor-based morphometry (TBM)], and surface or shape-based approaches (i.e. cortical thickness, multivariate shape analysis). These differences in methodologies and experimental designs may account for a substantial amount of the heterogeneity reported. For example, variable co-registration and choice of multiple comparison correction technique might cause differing results, particularly when the data is high dimensional such as in the VBM approach [6, 7].

In addition to image acquisition and processing technology, the choice of subjects included in each study also may contribute to inconsistencies in reported findings. For example, whereas many previous studies focused on the simple differentiation of PD from control subjects [8-10], there was a lack of focus on clinical heterogeneity regarding subtypes, disease durations, and stages. Indeed, several studies indicate that the spatial pattern of gray matter atrophy appears to correspond to clinical subtype and disease stage [11-15]. The purpose of this review is to summarize the current state of structural MRI research focused on gray matter changes in PD, particularly as it relates to PD progression, its ability to identify knowledge gaps and provide guidance for future research endeavors in MRI-based biomarker research. The idea that imaging might hold promise as a diagnostic tool in PD has been raised by some authors. Some studies, indeed, have aimed to show proof-of-concept that imaging can predict PD before its clinical onset [16-20], such as in rapid eye movement sleep behavioral disorder patients [21]. "At-risk" subjects, however, currently do not undergo neuroimaging within the preclinical phase of PD. The current review, therefore, will focus on how structural imaging relates to changes throughout the course of disease and its potential to provide biomarkers of PD progression.

\section{BASAL GANGLIA}

The basal ganglia have been a main imaging focus of interest in PD for several reasons. First, the putamen and caudate are directly downstream from the substantia nigra, which is the primary site of pathology in PD [22]. Degeneration of nigrostriatal terminals is thought to be associated with reduced striatal spine density [23, 24]. Interestingly, however, molecular labeling studies suggested that the deficits in nigrostriatal terminal densities tend to reach a floor at roughly five years, despite some evidence of continued nigral cell death $[25,26]$. Second, the traditional staging model by Braak et al. describes basal ganglia involvement relatively early in the disease, whereas cortical (especially neocortical) involvement is thought to occur later in disease. Third, cognitive decline is well documented in PD [27] even in earlier stages [28], and the striatum (via cortico-striatal connections) and hippocampus have been shown to play an important cognitive role in PD $[29,30]$. As such, there is an interest in utilizing these gray matter structures as markers of PD progression throughout several disease stages. Thus, we first will discuss the MRI findings in basal ganglia structures and their pathological and clinical implications during the course of PD progression.

\section{Putamen}

Nigrostriatal dopaminergic cell loss occurs in early $\mathrm{PD}$, with more than $50 \%$ of putamen dopaminergic terminals having been lost before clinical diagnosis of disease [31]. The putamen is one of the principle targets of nigrostriatal projections that degenerate in PD [31]. Thus, there has been particular interest in using 
measurements of putamen structure to detect PD onset and perhaps even to differentiate PD from other parkinsonisms [32, 33]. Indeed, putamen atrophy has been reported widely in PD and in a variety of disease stages [15, 34-43], but not necessarily in all studies [44-50]. Due to the fact that the putamen undergoes dopaminergic denervation well before clinical disease diagnosis [25], several studies have hypothesized that putamen atrophy would be diagnostically useful for PD and/or measuring progression. Whereas reduced putamen volume and/or atrophied shape are reported commonly in the PD literature, it is possible that a substantial amount of putamen atrophy occurs prior to disease onset, in parallel to nigrostriatal dopaminergic denervation. Ellmore et al. [18], for example, reported that subjects having rapid eye movement sleep behavioral disorder (RBD), a possible precursor to $\mathrm{PD}$, had lower putamen volumes than control subjects [39]. Geng et al. [38] reported similar findings among early-stage PD subjects [38]. In a shape analysis study, Sterling et al. [29] reported atrophy of the posterior putamen in early PD, localized within the known preferential pattern of dopaminergic denervation in PD [29]. Most recently, Lewis et al. [12] showed that putamen volume is lower and undergoes accelerated atrophy in the earliest stages of PD compared to control subjects [12]. A similar observation of accelerated atrophy in early PD also was observed by Tessa et al. [51]. In the study by Lewis et al. [12], however, putamen atrophy reached a floor after roughly five years of disease, similar to the changes in nigrostriatal dopaminergic terminals $[25,52]$, despite the fact that subjects continued to age and progress clinically. Taken together, these results suggest that putamen volume and/or shape could be useful not only in gauging PD-related pathology near the time of disease onset, but also might have the potential to detect changes in high-risk groups (such as RBD patients). Putamen volume and/or shape, however, may not provide the ideal measurements to track PD-related pathology progression after five years [25].

\section{Caudate}

Compared to the putamen, the caudate undergoes a slightly delayed loss of dopaminergic terminals in early PD, as nigrostriatal projections to the putamen degenerate preferentially [53]. Thus, one might expect a milder and/or later course of atrophy for the caudate in PD. Indeed, a number of studies have reported no significant difference in caudate volume between PD and control subjects, particularly in early-stage disease $[54,55]$, although some of those studies were likely limited by a small sample size $[38,39,44,45]$. Interestingly, two recent shape analyses have shown that the greatest extent of PD-related atrophy occurs in the head of the caudate, where dopaminergic terminal losses are known to be most severe $[29,56]$. In addition, there have been reports of accelerated caudate atrophy in early-stage PD, followed by a plateau $[12,51]$, suggesting that the greatest caudate atrophy also occurs in the earlier stages of disease. Thus, similar to putamen atrophy, caudate atrophy might not be the best metric to gauge progression in the later stages of PD.

\section{Substantia nigra, nucleus accumbens, and globus pallidus}

Fewer studies have reported atrophy of the substantia nigra, nucleus accumbens, or globus pallidus in PD. This is likely due to several reasons. First, these structures can be difficult to define precisely on T1-weighted MRI. The nucleus accumbens, for example, is continuous with the putamen and caudate. The globus pallidus, on the other hand, is a mixture of white and gray matter. Like the substantia nigra, it has two distinct functional components (internal and external) downstream from the striatum [57]. To investigate these structures, it is necessary to have extremely consistent and reliable imaging segmentation techniques, which are not widely available for the substantia nigra, nucleus accumbens, or globus pallidus. Second, these structures are relatively small, so there may be more measurement error due to partial volume effects.

Some evidence suggests that the substantia nigra volume may be decreased in PD [58]. Previous studies may have been limited by the difficulty of delineating precise boundaries of the substantia nigra using routine structural imaging techniques $[38,59$, $60]$. The substantia nigra accounts for only $0.5-0.6 \%$ of total brain volume, and partial volume effects can blur structural boundaries. More recent studies suggest that multimodal imaging may facilitate more precise detection of substantia nigra atrophy, even in early PD [58]. As noted previously, at least 50\% of nigral cells are lost before PD diagnosis, and this potentially could limit the utility of substantia nigra volume in tracking PD progression [31]. For the nucleus accumbens, a trend showing lower volume was reported by Tinaz et al. [41]. Studies investigating pallidal atrophy in PD roughly have been split 
between reporting atrophy [34, 46, 49], particularly with impaired cognition and more advanced disease stages [40, 42, 56, 61], and absence of atrophy [12, $38,39,44,45,54,55]$. Taken together, these reports suggest that the extent of pallidal atrophy is relatively weak and/or that there is a lack of reliable segmentation techniques to define pallidal anatomy.

\section{HIPPOCAMPUS AND AMYGDALA}

Hippocampal structure has been a topic of considerable interest in PD because of its well-documented role in memory decline and dementia [62]. Indeed, many studies have demonstrated an association between hippocampal atrophy and PD with dementia [15, 42, 61, 63-73], cognitive impairment [14, 15, $42,74,75]$, and visual hallucinations [71]. Within $\mathrm{PD}$, hippocampal atrophy has been associated consistently with impaired memory [14, 15, 65, 74, 76]. It also has been reported that hippocampal structural changes may be useful to predict future cognitive decline in PD [14]. In line with the notion that hippocampal structure is associated primarily with cognition, several studies have reported a lack of hippocampal atrophy in PD subjects without substantial cognitive impairment or dementia $[47,54,56,77,78]$.

Atrophy of the amygdala has been associated with dementia [42, 66, 69], cognitive impairment [15, 42], poor memory performance [70], and depression [77] in PD. Amygdala atrophy has been suggested to occur in several stages of PD, although results have been relatively inconsistent. Ibarretxe-Bilbao et al. [79], for example, demonstrated lower amygdala volumes and accelerated atrophy in early-stage PD [79, 80], which is in agreement with postmortem data suggesting amygdala pathology relatively early in disease [81]. Morgen et al. [82] reported amygdala atrophy among PD subjects without dementia, also in agreement with this notion [82]. A potential technical challenge in studying both the hippocampus and amygdala structures is that it is difficult to obtain accurate structural measurements from automatic segmentation tools [83]. Adding to this challenge is the relatively ambiguous boundary between the hippocampus and amygdala, which can appear as a continuous structure with standard structural magnetic resonance imaging modalities, and the multiple nuclei and neural substrates within each structure. Thus, to fully leverage the wealth of available structural imaging data that has been collected over many years, more accurate and precise segmentation techniques will be needed.

\section{THALAMUS}

The thalamus is the master relay station for brain structures, and it is intimately relevant to PD because it connects the basal ganglia to cortical regions. Although several studies have investigated thalamic structure in PD, few have reported significant atrophy, possibly suggesting that structural changes are mild or spatially focused in the thalamus. Lisanby et al. [34], Nagano-Saito et al. [61], and Lee et al. [46] for example, reported lower thalamus volumes in PD compared to controls. In contrast, some studies have found no difference in thalamus volume between PD and controls [35, 47]. Interestingly, Messina et al. [9] reported lower thalamus volumes in atypical parkinsonism compared to PD, suggesting that thalamic structure might be useful for differentiating PD from parkinsonian patients [47]. McKeown et al. [84] furthermore utilized shape analysis to investigate thalamus structure, reporting shape atrophy but no volume differences between PD and controls [84]. Thus, shape analysis might be more sensitive for detecting focused degeneration in specific thalamus nuclei and more refined imaging and segmentation techniques may be needed to investigate changes in these nuclei [85].

\section{CORTEX}

\section{Voxel- and tensor-based morphometry}

Voxel-based morphometry is a technique that allows group comparisons of gray matter density over the whole brain region. Several studies have utilized this analysis approach to investigate cortical structural changes in PD [86-89]. The majority of these studies have been cross-sectional [86, 88-97], although some were longitudinal [98] or had a longitudinal component [99]. The results from these studies, however, are variable and inconsistent. For example, several studies report no cortical structural changes in PD subjects [86, 93, 100-102] whereas others report decreased volume in the frontal lobe [90, $96,97]$, intraparietal sulcus [88], temporal lobe [89, $91,98,99]$, limbic and paralimbic areas [96, 98], anterior cingulate cortex [91], olfactory cortex [95], and parietal and occipital cortex [96, 97]. The discrepant results may be explained by subject heterogeneity, as most studies did not account for disease duration or clinical subtype [93, 95, 96, 103].

Some studies suggest that cortical structural changes may be more obvious in PD patients with 
cognitive deficits. For example, VBM studies have demonstrated decreased cortical volume in the anterior cingulate cortex $[89,91]$, temporal cortex [89, 91, 92, 98], frontal cortex [89, 90, 92], limbic and paralimbic areas [98], and parietal cortex [94]. PD patients with dementia [89-92, 94, 98, 101] appear to have more extensive cortical changes than those with PD mild cognitive impairment [99, 104, 105], although at least one study found no difference between PD patients with dementia and mild cognitive impairment [100].

Tensor based morphometry (TBM) was developed at the same time as VBM. It is different from VBM in that instead of relying on gray or white matter segmentation information, it uses directly the deformation information acquired during the image normalization step. Fewer studies have been performed in PD using the TBM technique. Two studies showed relatively few changes between PD and control subjects [106, 107]. The TBM technique has been reappraised in the neuroimaging field due to recent advances in brain image registration techniques [i.e. Diffeomorphic Anatomical Registration Through Exponentiated Lie Algebra (DARTEL) in the Statistical Parametric Mapping (SPM) toolbox and Symmetric Image Normalization in Advanced Normalization Tools (ANTS)] that allow reliable deformation information to be extracted from the image normalization $[108,109]$. A recent longitudinal study using TBM showed accelerated atrophy in several brain areas (frontal superior and middle gyrus, anterior cingulum, caudate, and thalamus) in cognitively normal early-stage PD subjects compared to controls, despite no significant differences at baseline [51].

When considering the results of VBM studies, it is important to note that such methodologies necessitate the use of statistical correction for many comparisons. Thus, although voxel-based techniques can facilitate the exploration of brain changes in PD, there may be many false negatives that reduce the usefulness for targeted hypothesis testing. On the other hand, the use of voxel-based techniques may allow for better localization of brain changes compared to segmentation-based techniques.

\section{Cortical thickness}

The loss of cortical thickness (the distance between the white matter - gray matter interface and the pia mater) is well documented in Alzheimer's disease [110]. Previous studies in PD, however, have yielded inconsistent results regarding the presence of cortical thinning at various stages. In cognitively normal and early PD subjects, past studies have reported minimal or no cortical thinning $[13,73,111,112]$. Lyoo et al. [113] reported weak correlations between cortical thickness and disease duration after adjusting for age and cognitive scores, although no control group was included for comparison [113]. One small study of $16 \mathrm{PD}$ and 15 control subjects, however, did report faster rates of cortical thinning in early PD, but still no difference in cortical thickness between PD and control subjects [80]. There is more substantial evidence, however, to suggest that lower cortical thickness may be related to cognitive decline or impairment $[13,73$, 112, 114-116], worsening motor scores [113, 114], and visual hallucinations [114] in PD. Pereira et al. [115], for example, demonstrated that PD subjects with mild cognitive impairment at an average of 6 months post-diagnosis had cognitive domain-specific patterns of cortical thinning [115]. Segura et al. [13] demonstrated similar findings in PD patients with mild cognitive impairment, although disease duration was approximately 6.4 years [13]. A recent study by Mak et al. [117] suggested that whereas PD subjects with normal cognition have relatively minimal cortical thinning, PD subjects with cognitive impairment show faster cortical thinning [117]. Finally, there is a well-documented relationship between lower cortical thickness and PD-related dementia [73, 112, 114]. Combining cortical thickness with hippocampal volume, Zarei et al., in 2013, reported 80\% accuracy in identifying PD patients with dementia [73].

The results of cortical thickness studies are in agreement with the documented trajectory of Lewy pathology, which is thought to involve cortical structures at a later stage than many subcortical structures [118]. It should be noted, however, that even in later-stage PD there is little evidence of cortical thinning if cognition is not impaired. Hwang et al., in 2013, for example, reported thinner cortices in PD dementia patients compared to PD patients with normal cognition, despite the fact that PD patients with dementia had a shorter disease duration. Thus, cortical thinning, as a marker of disease progression, seems difficult to separate from dementia, which is a consequence of the natural progression of PD [30]. Interestingly, Lewy pathology in PD is known to occur in layer-specific patterns in the cortex, preferentially affecting certain cortical layers depending upon the brain region. To understand the exact mechanisms, future postmortem studies will need to determine the direct relationships between cortical 
thickness and pathologic changes that are known to occur in PD cortices [118-121] and account for the co-existence of Alzheimer's pathology.

\section{Cortical gyrification}

Most studies of cortical structure in PD have utilized cortical thickness as the sole metric to gauge cortical atrophy. It is important to consider, however, the layered structure of the cortex and its columnar organization. Acknowledging these structural intricacies, several recent studies have focused on the folding structure (gyrification indices) of the cortex in PD. Historically, the gyrification index offered a method to quantify cortical folding of a two-dimensional brain slice, defined as the ratio of cortical surface over an outer perimeter [122]. Local gyrification index is a newer, image-based metric to quantify gyrification in three dimensions [123]. One study investigating cortical folding in PD reported relatively diffuse reductions in a PD cohort having disease duration of approximately 4 years compared to control subjects [124]. Another study found no differences in cortical gyrification between PD and control subjects, but reported inverse correlations between cortical gyrification in several frontal and parietal areas and a composite score of disease severity that included Hoehn-Yahr stage, cognitive impairment, and disease duration [73]. In this particular study, it was unclear whether dementia (known to affect cortical structure) had contributed to the lower gyrification indices seen in more advancedstages PD subjects. Recently, however, our group published a combined exploration and validation study of PD subjects who had no dementia at baseline. The results suggested that PD subjects having disease duration less than five years undergo accelerated loss of gyrification over time, although they did not have significantly lower gyrification compared to controls. Subjects having disease duration greater than five years showed significantly lower gyrification indices in several key areas (supramarginal, inferior parietal, superior frontal, precentral, and postcentral) in the absence of dementia [11]. Taken together, these results suggest that PD subjects undergo loss of cortical folding as disease progresses.

Future studies should focus on developing and implementing more sophisticated methods of quantifying cortical folding, which may be useful to measure cortical disease progression in PD. In addition, unlike the pattern of atrophy observed in striatal structures, it seems that a "floor" of gyrification loss does not become discernable until much later in disease. Further longitudinal studies of more advanced patients are needed in order to determine whether these losses continue through the entirety of the disease.

\section{CHALLENGES IN STRUCTURAL IMAGING AND THE FUTURE}

Despite the promise of structural imaging for assessing macroscopic changes in gray matter associated with PD and tracking disease progression at various stages of disease, there are several major challenges that currently hinder practical implementation in clinical studies. One such problem is the lack of automatic methods that can precisely define the boundaries of gray matter structures. The effect sizes of gray matter atrophy also are often very small (roughly a loss of a few percent is typical in PD). This makes it critical to reduce measurement error in the delineation of gray matter structures. Unfortunately, the most widely used segmentation techniques still are prone to low precision and systematic bias [125], whereas manual segmentation is extremely time consuming and susceptible to issues of rater and left-right bias [126]. Precise and unbiased definition of structures is particularly important for shape analysis studies, where there is a loss of power if correction for multiple comparisons is utilized. Thus, the techniques used to control false positives in shape analysis must also be optimized for power. Finally, automatic segmentation methods have the potential for bias in neurodegenerative diseases [125]. Thus, there is a need to develop new technologies that can define the precise boundaries of gray matter structures in an unbiased manner. Such technologies would benefit structural imaging not only in PD research, but in a wide range of neurodegenerative diseases.

Lastly, it is important to consider the scientific utility, clinical implications, and limits of structural gray matter imaging in PD. Some studies have attempted to evaluate structural imaging as a tool for early $\mathrm{PD}$ diagnosis and differentiating between PD and atypical parkinsonisms. The weight of the literature, however, suggests that there is not enough statistical separation of single-structure measurements between PD and non-PD subjects to be of clinical use. A recent study, however, suggested that utilizing patterns of atrophy across several structures may be of greater utility for this task [127]. Similarly, many studies have attempted to link clinical symptoms and/or functional deficits in PD with specific brain structures, 
with variable success. Overall, however, the body of existing literature suggests that many structures are related to a variety of clinical symptoms and/or functional deficits in PD, and vice versa. This notion is not surprising because clinical functions depend upon multiple brain structural networks and the PD process affects multiple brain structures [128]. Thus, future studies of gray matter structures and their functional implications may seek to identify patterns of morphologic changes over time. This can be accomplished using a variety of network- and multivariable-based techniques [129] and combined with different MRI modalities. If these issues can be addressed and accuracy improved substantially, then structural imaging might have a particularly useful role in monitoring PD progression and predicting outcomes at the individual level.

\section{ACKNOWLEDGMENTS}

We would like to acknowledge the reviewers for their constructive feedback and the following grant funding sources: NINDS (NS060722 and NS082151 to $\mathrm{XH}$ ), the Hershey Medical Center GCRC (NIH M01RR10732), GCRC Construction Grant (C06RR016499), Pennsylvania Department of Health Tobacco CURE Funds.

\section{STUDY FUNDING}

NINDS (NS060722 and NS082151 to XH), the Hershey Medical Center GCRC (NIH M01RR10 732), GCRC Construction Grant (C06RR016499), Pennsylvania Department of Health Tobacco CURE Funds.

\section{CONFLICT OF INTEREST DISCLOSURES}

The authors disclose no conflicts of interest.

\section{REFERENCES}

[1] Perez-Lloret S, Flabeau O, Fernagut PO, Traon PL, Rey MV, Foubert-Samier A, Tison F, Rascol O, \& Meissner WG (2015) Current concepts in the treatment of multiple system atrophy. Mov Disord Clin Pract, 2, 6-16.

[2] Lang AE (2005) Treatment of progressive Psupranuclear palsy and corticobasal degeneration. Mov Disord, 20, S83-S91.

[3] Hart RG, Pearce LA, Ravina BM, Yaltho TC, \& Marler JR (2009) Neuroprotection trials in Parkinson's disease: Systematic review. Mov Disord, 24, 647-654.
[4] Palmer JL, Coats MA, Roe CM, Hanko SM, Xiong C, \& Morris JC (2010) Unified Parkinson's Disease Rating Scale-Motor Exam: Inter-rater reliability of advanced practice nurse and neurologist assessments. $J$ Adv Nurs, 66, 1382-1387.

[5] Postuma RB, Aarsland D, Barone P, Burn DJ, Hawkes CH, Oertel W, \& Ziemssen T (2012) Identifying prodromal Parkinson's disease: Pre-motor disorders in Parkinson's disease. Mov Disord, 27, 617-626.

[6] Pan PL, Song W, \& Shang HF (2012) Voxel-wise meta-analysis of gray matter abnormalities in idiopathic Parkinson's disease. Eur J Neurol, 19, 199-206.

[7] Agosta F, Canu E, Stojkovic T, Pievani M, Tomic A, Sarro L, Dragasevic N, Copetti M, Comi G, Kostic VS, \& Filippi M (2013) The topography of brain damage at different stages of Parkinson's disease. Hum Brain Mapp, 34, 27982807.

[8] Schulz JB, Skalej M, Wedekind D, Luft AR, Abele M, Voigt K, Dichgans J, \& Klockgether T (1999) Magnetic resonance imaging-based volumetry differentiates idiopathic Parkinson's syndrome from multiple system atrophy and progressive supranuclear palsy. Ann Neurol, 45, 65-74.

[9] Messina D, Cerasa A, Condino F, Arabia G, Novellino F, Nicoletti G, Salsone M, Morelli M, Lanza PL, \& Quattrone A (2011) Patterns of brain atrophy in Parkinson's disease, progressive supranuclear palsy and multiple system atrophy. Parkinsonism Relat Disord, 17, 172-176.

[10] Ghaemi M, Hilker R, Rudolf J, Sobesky J, \& Heiss WD (2002) Differentiating multiple system atrophy from Parkinson's disease: Contribution of striatal and midbrain MRI volumetry and multi-tracer PET imaging. J Neurol Neurosurg Psychiatry, 73, 517-523.

[11] Sterling NW, Wang M, Zhang L, Lee EY, Du G, Lewis MM, Styner M, \& Huang X (2016) Stage-dependent loss of cortical gyrification as Parkinson's disease "unfolds". Neurology, 86, 1143-1151.

[12] Lewis MM, Du G, Lee EY, Nasralah Z, Sterling NW, Zhang L, Wagner D, Kong L, Troster AI, Styner M, Eslinger PJ, Mailman RB, \& Huang X (2015) The pattern of gray matter atrophy in Parkinson's disease differs in cortical and subcortical regions. J Neurol, Oct 20. doi: 10.1007/s00415-015-7929-7 (Epub ahead of print).

[13] Segura B, Baggio HC, Marti MJ, Valldeoriola F, Compta Y, Garcia-Diaz AI, Vendrell P, Bargallo N, Tolosa E, \& Junque C (2014) Cortical thinning associated with mild cognitive impairment in Parkinson's disease. Mov Disord, 29, 1495-1503.

[14] Weintraub D, Dietz N, Duda JE, Wolk DA, Doshi J, Xie SX, Davatzikos C, Clark CM, \& Siderowf A (2012) Alzheimer's disease pattern of brain atrophy predicts cognitive decline in Parkinson's disease. Brain, 135, 170-180.

[15] Weintraub D, Doshi J, Koka D, Davatzikos C, Siderowf AD, Duda JE, Wolk DA, Moberg PJ, Xie SX, \& Clark CM (2011) Neurodegeneration across stages of cognitive decline in Parkinson disease. Arch Neurol, 68, 1562-1568.

[16] Murray ME, Ferman TJ, Boeve BF, Przybelski SA, Lesnick TG, Liesinger AM, Senjem ML, Gunter JL, Preboske GM, Lowe VJ, Vemuri P, Dugger BN, Knopman DS, Smith GE, Parisi JE, Silber MH, Graff-Radford NR, Petersen RC, Jack CR Jr, Dickson DW, \& Kantarci K (2013) MRI and pathology of REM sleep behavior disorder in dementia with Lewy bodies. Neurology, 81, 1681-1689. 
[17] Dang-Vu TT, Gagnon JF, Vendette M, Soucy JP, Postuma RB, \& Montplaisir J (2012) Hippocampal perfusion predicts impending neurodegeneration in REM sleep behavior disorder. Neurology, 79, 2302-2306.

[18] Ellmore TM, Hood AJ, Castriotta RJ, Stimming EF, Bick RJ, \& Schiess MC (2010) Reduced volume of the putamen in REM sleep behavior disorder patients. Parkinsonism Relat Disord, 16, 645-649.

[19] Ellmore TM, Castriotta RJ, Hendley KL, Aalbers BM, Furr-Stimming E, Hood AJ, Suescun J, Beurlot MR, Hendley RT, \& Schiess MC (2013) Altered nigrostriatal and nigrocortical functional connectivity in rapid eye movement sleep behavior disorder. Sleep, 36, 1885-1892.

[20] Unger MM, Moller JC, Stiasny-Kolster K, Mankel K, Berg D, Walter U, Hoeffken H, Mayer G, \& Oertel WH(2008) Assessment of idiopathic rapid-eye-movement sleep behavior disorder by transcranial sonography, olfactory function test, and FP-CIT-SPECT. Mov Disord, 23, 596-599.

[21] Postuma RB, Aarsland D, Barone P, Burn DJ, Hawkes CH, Oertel W, \& Ziemssen T (2012) Identifying prodromal Parkinson's disease: Pre-motor disorders in Parkinson's disease. Mov Disord, 27, 617-626.

[22] Jellinger KA (2012) Neuropathology of sporadic Parkinson's disease: Evaluation and changes of concepts. Mov Disord, 27, 8-30.

[23] Villalba RM, \& Smith Y (2010) Striatal spine plasticity in Parkinson's disease. Front Neuroanat, 4, 133.

[24] Villalba RM, \& Smith Y (2013) Differential striatal spine pathology in Parkinson's disease and cocaine addiction: A key role of dopamine? Neuroscience, 251, 2-20.

[25] Maetzler W, Liepelt I, \& Berg D (2009) Progression of Parkinson's disease in the clinical phase: Potential markers. Lancet Neurol, 8, 1158-1171.

[26] Perlmutter JS, \& Norris SA (2014) Neuroimaging biomarkers for Parkinson disease: Facts and fantasy. Ann Neurol, 76, 769-783.

[27] Leroi I, McDonald K, Pantula H, \& Harbishettar V (2012) Cognitive impairment in Parkinson disease: Impact on quality of life, disability, and caregiver burden. $J$ Geriatr Psychiatry Neurol, 25, 208-214.

[28] Pedersen KF, Larsen JP, Tysnes OB, \& Alves G (2013) Prognosis of mild cognitive impairment in early Parkinson disease: The Norwegian ParkWest study. JAMA Neurol, 70, 580-586.

[29] Sterling NW, Du G, Lewis MM, Dimaio C, Kong L, Eslinger PJ, Styner M, \& Huang X (2013) Striatal shape in Parkinson's disease. Neurobiol Aging, 34, 2510-2516.

[30] Aarsland D, Zaccai J, \& Brayne C (2005) A systematic review of prevalence studies of dementia in Parkinson's disease. Mov Disord, 20, 1255-1263.

[31] Kish SJ, Shannak K, \& Hornykiewicz O (1988) Uneven pattern of dopamine loss in the striatum of patients with idiopathic Parkinson's disease. Pathophysiologic and clinical implications. $N$ Engl J Med, 318, 876-880.

[32] Paviour DC, Price SL, Jahanshahi M, Lees AJ, \& Fox NC (2006) Regional brain volumes distinguish PSP, MSA-P, and PD: MRI-based clinico-radiological correlations. Mov Disord, 21, 989-996.

[33] Shin HY, Kang SY, Yang JH, Kim HS, Lee MS, \& Sohn YH (2007) Use of the putamen/caudate volume ratio for early differentiation between parkinsonian variant of multiple system atrophy and Parkinson disease. J Clin Neurol, 3, 79-81.
[34] Lisanby SH, McDonald WM, Massey EW, Doraiswamy PM, Rozear M, Boyko OB, Krishnan KR, \& Nemeroff C (1993) Diminished subcortical nuclei volumes in Parkinson's disease by MR imaging. J Neural Transm Suppl, 40, 13-21.

[35] O'Neill J, Schuff N, Marks WJ Jr, Feiwell R, Aminoff MJ, \& Weiner MW (2002) Quantitative 1H magnetic resonance spectroscopy and MRI of Parkinson's disease. Mov Disord, 17, 917-927.

[36] Atasoy HT, Nuyan O, Tunc T, Yorubulut M, Unal AE, \& Inan LE (2004) T2-weighted MRI in Parkinson's disease; substantia nigra pars compacta hypointensity correlates with the clinical scores. Neurol India, 52, 332-337.

[37] Krabbe K, Karlsborg M, Hansen A, Werdelin L, Mehlsen J, Larsson HB, \& Paulson OB (2005) Increased intracranial volume in Parkinson's disease. J Neurol Sci, 239, 45-52.

[38] Geng DY, Li YX, \& Zee CS (2006) Magnetic resonance imaging-based volumetric analysis of basal ganglia nuclei and substantia nigra in patients with Parkinson's disease. Neurosurgery, 58, 256-262; discussion 256-262.

[39] Ellmore TM, Hood AJ, Castriotta RJ, Stimming EF, Bick RJ, \& Schiess MC (2010) Reduced volume of the putamen in REM sleep behavior disorder patients. Parkinsonism Relat Disord, 16, 645-649.

[40] Tambasco N, Belcastro V, Sarchielli P, Floridi P, Pierguidi L, Menichetti C, Castrioto A, Chiarini P, Parnetti L, Eusebi P, Calabresi P, \& Rossi A (2011) A magnetization transfer study of mild and advanced Parkinson's disease. Eur J Neurol, 18, 471-477.

[41] Tinaz S, Courtney MG, \& Stern CE (2011) Focal cortical and subcortical atrophy in early Parkinson's disease. Mov Disord, 26, 436-441.

[42] Melzer TR, Watts R, MacAskill MR, Pitcher TL, Livingston L, Keenan RJ, Dalrymple-Alford JC, \& Anderson TJ (2012) Grey matter atrophy in cognitively impaired Parkinson's disease. J Neurol Neurosurg Psychiatry, 83, 188-194.

[43] Pitcher TL, Melzer TR, Macaskill MR, Graham CF, Livingston L, Keenan RJ, Watts R, Dalrymple-Alford JC, \& Anderson TJ (2012) Reduced striatal volumes in Parkinson's disease: A magnetic resonance imaging study. Transl Neurodegener, 1, 17.

[44] Schulz JB, Skalej M, Wedekind D, Luft AR, Abele M, Voigt K, Dichgans J, \& Klockgether T (1999) Magnetic resonance imaging-based volumetry differentiates idiopathic Parkinson's syndrome from multiple system atrophy and progressive supranuclear palsy. Ann Neurol, 45, 65-74.

[45] Ghaemi M, Hilker R, Rudolf J, Sobesky J, \& Heiss WD (2002) Differentiating multiple system atrophy from Parkinson's disease: Contribution of striatal and midbrain MRI volumetry and multi-tracer PET imaging. J Neurol Neurosurg Psychiatry, 73, 517-523.

[46] Lee SH, Kim SS, Tae WS, Lee SY, Choi JW, Koh SB, \& Kwon DY (2011) Regional volume analysis of the Parkinson disease brain in early disease stage: Gray matter, white matter, striatum, and thalamus. AJNR Am J Neuroradiol, 32, 682-687.

[47] Messina D, Cerasa A, Condino F, Arabia G, Novellino F, Nicoletti G, Salsone M, Morelli M, Lanza PL, \& Quattrone A (2011) Patterns of brain atrophy in Parkinson's disease, progressive supranuclear palsy and multiple system atrophy. Parkinsonism Relat Disord, 17, 172-176. 
[48] Seibert TM, Murphy EA, Kaestner EJ, \& Brewer JB (2012) Interregional correlations in Parkinson disease and Parkinson-related dementia with resting functional MR imaging. Radiology, 263, 226-234.

[49] Brenneis C, Seppi K, Schocke MF, Muller J, Luginger E, Bosch S, Loscher WN, Buchel C, Poewe W, \& Wenning GK (2003) Voxel-based morphometry detects cortical atrophy in the Parkinson variant of multiple system atrophy. Mov Disord, 18, 1132-1138.

[50] Bonneville F, Welter ML, Elie C, du Montcel ST, Hasboun D, Menuel C, Houeto JL, Bonnet AM, Mesnage V, Pidoux B, Navarro S, Cornu P, Agid Y, \& Dormont D (2005) Parkinson disease, brain volumes, and subthalamic nucleus stimulation. Neurology, 64, 1598-1604.

[51] Tessa C, Lucetti C, Giannelli M, Diciotti S, Poletti M, Danti S, Baldacci F, Vignali C, Bonuccelli U, Mascalchi M, \& Toschi N (2014) Progression of brain atrophy in the early stages of Parkinson's disease: A longitudinal tensor-based morphometry study in de novo patients without cognitive impairment. Hum Brain Mapp, 35, 3932-3944.

[52] Lee CS, Schulzer M, Mak E, Hammerstad JP, Calne S, \& Calne DB (1995) Patterns of asymmetry do not change over the course of idiopathic parkinsonism: Implications for pathogenesis. Neurology, 45, 435-439.

[53] Kish SJ, Shannak K, \& Hornykiewicz O (1988) Uneven pattern of dopamine loss in the striatum of patients with idiopathic Parkinson's disease. Pathophysiologic and clinical implications. N Engl J Med, 318, 876-880.

[54] Cordato NJ, Pantelis C, Halliday GM, Velakoulis D, Wood SJ, Stuart GW, Currie J, Soo M, Olivieri G, Broe GA, \& Morris JG (2002) Frontal atrophy correlates with behavioural changes in progressive supranuclear palsy. Brain, 125, 789-800.

[55] Almeida OP, Burton EJ, McKeith I, Gholkar A, Burn D, \& O'Brien JT (2003) MRI study of caudate nucleus volume in Parkinson's disease with and without dementia with Lewy bodies and Alzheimer's disease. Dement Geriatr Cogn Disord, 16, 57-63.

[56] Apostolova LG, Beyer M, Green AE, Hwang KS, Morra JH, Chou YY, Avedissian C, Aarsland D, Janvin CC, Larsen JP, Cummings JL, \& Thompson PM (2010) Hippocampal, caudate, and ventricular changes in Parkinson's disease with and without dementia. Mov Disord, 25, 687695.

[57] Mancall EL, \& Brock DG (2011) Gray's Clinical Neuroanatomy, Elsevier Health Sciences.

[58] Ziegler DA, Wonderlick JS, Ashourian P, Hansen LA, Young JC, Murphy AJ, Koppuzha CK, Growdon JH, \& Corkin S (2013) Substantia nigra volume loss before basal forebrain degeneration in early Parkinson disease. JAMA Neurol, 70, 241-247.

[59] Schocke MF, Seppi K, Esterhammer R, Kremser C, Mair KJ, Czermak BV, Jaschke W, Poewe W, \& Wenning GK (2004) Trace of diffusion tensor differentiates the Parkinson variant of multiple system atrophy and Parkinson's disease. Neuroimage, 21, 1443-1451.

[60] Seppi K, Schocke M, Esterhammer R, Kremser C, Brenneis C, Mueller J, Boesch S, Jaschke W, Poewe W, \& Wenning G (2003) Diffusion-weighted imaging discriminates progressive supranuclear palsy from PD, but not from the parkinson variant of multiple system atrophy. Neurology, 60, 922-927.

[61] Nagano-Saito A, Washimi Y, Arahata Y, Kachi T, Lerch JP, Evans AC, Dagher A, \& Ito K (2005) Cerebral atrophy and its relation to cognitive impairment in Parkinson disease. Neurology, 64, 224-229.

[62] den Heijer T, van der Lijn F, Koudstaal PJ, Hofman A, van der Lugt A, Krestin GP, Niessen WJ, \& Breteler MM (2010) A 10-year follow-up of hippocampal volume on magnetic resonance imaging in early dementia and cognitive decline. Brain, 133, 1163-1172.

[63] Laakso MP, Partanen K, Riekkinen P, Lehtovirta M, Helkala EL, Hallikainen M, Hanninen T, Vainio P, \& Soininen H (1996) Hippocampal volumes in Alzheimer's disease, Parkinson's disease with and without dementia, and in vascular dementia: An MRI study. Neurology, 46, 678-681.

[64] Riekkinen P Jr, Kejonen K, Laakso MP, Soininen H, Partanen K, \& Riekkinen M (1998) Hippocampal atrophy is related to impaired memory, but not frontal functions in non-demented Parkinson's disease patients. Neuroreport, 9, 1507-1511.

[65] Camicioli R, Moore MM, Kinney A, Corbridge E, Glassberg K, \& Kaye JA (2003) Parkinson's disease is associated with hippocampal atrophy. Mov Disord, 18, 784-790.

[66] Junque C, Ramirez-Ruiz B, Tolosa E, Summerfield C, Marti MJ, Pastor P, Gomez-Anson B, \& Mercader JM (2005) Amygdalar and hippocampal MRI volumetric reductions in Parkinson's disease with dementia. Mov Disord, 20, 540-544.

[67] Summerfield C, Junque C, Tolosa E, Salgado-Pineda P, Gomez-Anson B, Marti MJ, Pastor P, Ramirez-Ruiz B, \& Mercader J (2005) Structural brain changes in Parkinson disease with dementia: A voxel-based morphometry study. Arch Neurol, 62, 281-285.

[68] Tam CW, Burton EJ, McKeith IG, Burn DJ, \& O’Brien JT (2005) Temporal lobe atrophy on MRI in Parkinson disease with dementia: A comparison with Alzheimer disease and dementia with Lewy bodies. Neurology, 64, 861-865.

[69] Beyer MK, Janvin CC, Larsen JP, \& Aarsland D (2007) A magnetic resonance imaging study of patients with Parkinson's disease with mild cognitive impairment and dementia using voxel-based morphometry. J Neurol Neurosurg Psychiatry, 78, 254-259.

[70] Bouchard TP, Malykhin N, Martin WR, Hanstock CC, Emery DJ, Fisher NJ, \& Camicioli RM (2008) Age and dementia-associated atrophy predominates in the hippocampal head and amygdala in Parkinson's disease. Neurobiol Aging, 29, 1027-1039.

[71] Ibarretxe-Bilbao N, Ramirez-Ruiz B, Tolosa E, Marti MJ, Valldeoriola F, Bargallo N, \& Junque C (2008) Hippocampal head atrophy predominance in Parkinson's disease with hallucinations and with dementia. J Neurol, 255, 1324-1331.

[72] Goldman JG, Stebbins GT, Bernard B, Stoub TR, Goetz CG, \& deToledo-Morrell L (2012) Entorhinal cortex atrophy differentiates Parkinson's disease patients with and without dementia. Mov Disord, 27, 727-734.

[73] Zarei M, Ibarretxe-Bilbao N, Compta Y, Hough M, Junque C, Bargallo N, Tolosa E, \& Marti MJ (2013) Cortical thinning is associated with disease stages and dementia in Parkinson's disease. J Neurol Neurosurg Psychiatry, 84, 875-881.

[74] Bruck A, Kurki T, Kaasinen V, Vahlberg T, \& Rinne JO (2004) Hippocampal and prefrontal atrophy in patients with early non-demented Parkinson's disease is related to cognitive impairment. J Neurol Neurosurg Psychiatry, 75, 1467-1469. 
[75] Apostolova L, Alves G, Hwang KS, Babakchanian S, Bronnick KS, Larsen JP, Thompson PM, Chou Y-Y, Tysnes OB, \& Vefring HK (2012) Hippocampal and ventricular changes in Parkinson's disease mild cognitive impairment. Neurobiol Aging, 33, 2113-2124.

[76] Jokinen P, Bruck A, Aalto S, Forsback S, Parkkola R, \& Rinne JO (2009) Impaired cognitive performance in Parkinson's disease is related to caudate dopaminergic hypofunction and hippocampal atrophy. Parkinsonism Relat Disord, 15, 88-93.

[77] Surdhar I, Gee M, Bouchard T, Coupland N, Malykhin N, \& Camicioli R (2012) Intact limbic-prefrontal connections and reduced amygdala volumes in Parkinson's disease with mild depressive symptoms. Parkinsonism Relat Disord, 18, 809-813.

[78] Carlesimo GA, Piras F, Assogna F, Pontieri FE, Caltagirone C, \& Spalletta G (2012) Hippocampal abnormalities and memory deficits in Parkinson disease: A multimodal imaging study. Neurology, 78, 1939-1945.

[79] Ibarretxe-Bilbao N, Junque C, Tolosa E, Marti MJ, Valldeoriola F, Bargallo N, \& Zarei M (2009) Neuroanatomical correlates of impaired decision-making and facial emotion recognition in early Parkinson's disease. Eur J Neurosci, 30, 1162-1171.

[80] Ibarretxe-Bilbao N, Junque C, Segura B, Baggio HC, Marti MJ, Valldeoriola F, Bargallo N, \& Tolosa E (2012) Progression of cortical thinning in early Parkinson's disease. Mov Disord, 27, 1746-1753.

[81] Goedert M, Spillantini MG, Del Tredici K, \& Braak H (2013) 100 years of Lewy pathology. Nat Rev Neurol, 9, 13-24.

[82] Morgen K, Sammer G, Weber L, Aslan B, Müller C, Bachmann GF, Sandmann D, Oechsner M, Vaitl D, Kaps M, \& Reuter I (2011) Structural brain abnormalities in patients with Parkinson disease: A comparative voxel-based analysis using T1-weighted MR imaging and magnetization transfer imaging. AJNR Am J Neuroradiol, 32, 2080-2086.

[83] Morey RA, Petty CM, Xu Y, Hayes JP, Wagner HR, Lewis DV, LaBar KS, Styner M, \& McCarthy G (2009) A comparison of automated segmentation and manual tracing for quantifying hippocampal and amygdala volumes. $\mathrm{Neu}$ roimage, 45, 855-866.

[84] McKeown MJ, Uthama A, Abugharbieh R, Palmer S, Lewis M, \& Huang X (2008) Shape (but not volume) changes in the thalami in Parkinson disease. BMC Neurol, 8,8 .

[85] Halliday GM (2009) Thalamic changes in Parkinson's disease. Parkinsonism Relat Disord, 15(Supp13), S152-S155.

[86] Brenneis C, Seppi K, Schocke MF, Muller J, Luginger E, Bosch S, Loscher WN, Buchel C, Poewe W, \& Wenning GK (2003) Voxel-based morphometry detects cortical atrophy in the Parkinson variant of multiple system atrophy. Mov Disord, 18, 1132-1138.

[87] Burton EJ, McKeith IG, Burn DJ, Williams ED, \& O'Brien JT (2004) Cerebral atrophy in Parkinson's disease with and without dementia: A comparison with Alzheimer's disease, dementia with Lewy bodies and controls. Brain, 127, 791-800

[88] Cordato NJ, Duggins AJ, Halliday GM, Morris JG, \& Pantelis C (2005) Clinical deficits correlate with regional cerebral atrophy in progressive supranuclear palsy. Brain, 128, 1259-1266.

[89] Nagano-Saito A, Washimi Y, Arahata Y, Kachi T, Lerch JP, Evans AC, Dagher A, \& Ito K (2005) Cerebral atrophy and its relation to cognitive impairment in Parkinson disease. Neurology, 64, 224-229.

[90] Burton EJ, McKeith IG, Burn DJ, Williams ED, \& OBrien JT (2004) Cerebral atrophy in Parkinson's disease with and without dementia: A comparison with Alzheimer's disease, dementia with Lewy bodies and controls. Brain, 127, 791-800

[91] Summerfield C, Junque C, Tolosa E, Salgado-Pineda P, Gomez-Anson B, Marti MJ, Pastor P, Ramirez-Ruiz B, \& Mercader J (2005) Structural brain changes in Parkinson disease with dementia: A voxel-based morphometry study. Arch Neurol, 62, 281-285.

[92] Feldmann A, Illes Z, Kosztolanyi P, Illes E, Mike A, Kover F, Balas I, Kovacs N, \& Nagy F (2008) Morphometric changes of gray matter in Parkinson's disease with depression: A voxel-based morphometry study. Mov Disord, 23, 42-46.

[93] Ibarretxe-Bilbao N, Junque C, Tolosa E, Marti MJ, Valldeoriola F, Bargallo N, \& Zarei M (2009) Neuroanatomical correlates of impaired decision-making and facial emotion recognition in early Parkinson's disease. Eur J Neurosci, 30, 1162-1171.

[94] Sanchez-Castaneda C, Rene R, Ramirez-Ruiz B, Campdelacreu J, Gascon J, Falcon C, Calopa M, Jauma S, Juncadella M, \& Junque C (2009) Correlations between gray matter reductions and cognitive deficits in dementia with Lewy Bodies and Parkinson's disease with dementia. Mov Disord, 24, 1740-1746.

[95] Morgen K, Sammer G, Weber L, Aslan B, Muller C, Bachmann GF, Sandmann D, Oechsner M, Vaitl D, Kaps M, \& Reuter I (2011) Structural brain abnormalities in patients with Parkinson disease: A comparative voxel-based analysis using T1-weighted MR imaging and magnetization transfer imaging. AJNR Am J Neuroradiol, 32, 2080-2086.

[96] Rosenberg-Katz K, Herman T, Jacob Y, Giladi N, Hendler T, \& Hausdorff JM (2013) Gray matter atrophy distinguishes between Parkinson disease motor subtypes. Neurology, 80, 1476-1484.

[97] Pagonabarraga J, Soriano-Mas C, Llebaria G, Lopez-Sola M, Pujol J, \& Kulisevsky J (2014) Neural correlates of minor hallucinations in non-demented patients with Parkinson's disease. Parkinsonism Relat Disord, 20, 290 296.

[98] Ramirez-Ruiz B, Marti MJ, Tolosa E, Bartres-Faz D, Summerfield C, Salgado-Pineda P, Gomez-Anson B, \& Junque C (2005) Longitudinal evaluation of cerebral morphological changes in Parkinson's disease with and without dementia. J Neurol, 252, 1345-1352.

[99] Weintraub D, Dietz N, Duda JE, Wolk D, Doshi J, Xie SX, Davatzikos C, Clark CM, \& Siderowf A (2012) Alzheimer's disease pattern of brain atrophy predicts cognitive decline in Parkinson's disease. Brain, 135, 170-180.

[100] Weintraub D, Doshi J, Koka D, Davatzikos C, Siderowf AD, Duda JE, Wolk DA, Moberg PJ, Xie SX, \& Clark CM (2011) Neurodegeneration across stages of cognitive decline in Parkinson disease. Arch Neurol, 68, 1562-1568.

[101] Melzer TR, Watts R, MacAskill MR, Pitcher TL, Livingston L, Keenan RJ, Dalrymple-Alford JC, \& Anderson TJ (2012) Grey matter atrophy in cognitively impaired Parkinson's disease. J Neurol Neurosurg Psychiatry, 83, 188-194.

[102] Ellfolk U, Joutsa J, Rinne JO, Parkkola R, Jokinen P, \& Karrasch M (2013) Brain volumetric correlates of memory in early Parkinson's disease. J Parkinsons Dis, 3, 593-601. 
[103] Benninger DH, Thees S, Kollias SS, Bassetti CL, \& Waldvogel D (2009) Morphological differences in Parkinson's disease with and without rest tremor. J Neurol, 256, 256263.

[104] Beyer MK, Janvin CC, Larsen JP, \& Aarsland D (2007) A magnetic resonance imaging study of patients with Parkinson's disease with mild cognitive impairment and dementia using voxel-based morphometry. J Neurol Neurosurg Psychiatry, 78, 254-259.

[105] Song SK, Lee JE, Park HJ, Sohn YH, Lee JD, \& Lee $\mathrm{PH}$ (2011) The pattern of cortical atrophy in patients with Parkinson's disease according to cognitive status. Mov Disord, 26, 289-296.

[106] Menke RA, Szewczyk-Krolikowski K, Jbabdi S, Jenkinson M, Talbot K, Mackay CE, \& Hu M (2014) Comprehensive morphometry of subcortical grey matter structures in early-stage Parkinson's disease. Hum Brain Mapp, 35, 1681-1690.

[107] Agosta F, Canu E, Stojkovic T, Pievani M, Tomic A, Sarro L, Dragasevic N, Copetti M, Comi G, Kostic VS, \& Filippi M (2013) The topography of brain damage at different stages of Parkinson's disease. Hum Brain Mapp, 34, 27982807.

[108] Hua X, Hibar DP, Ching CR, Boyle CP, Rajagopalan P, Gutman BA, Leow AD, Toga AW, Jack CR Jr, Harvey D, Weiner MW, Thompson PM, \& Alzheimer's Disease Neuroimaging I (2013) Unbiased tensor-based morphometry: Improved robustness and sample size estimates for Alzheimer's disease clinical trials. Neuroimage, 66, 648661.

[109] Tessa C, Lucetti C, Giannelli M, Diciotti S, Poletti M, Danti S, Baldacci F, Vignali C, Bonuccelli U, Mascalchi M, \& Toschi N (2014) Progression of brain atrophy in the early stages of Parkinson's disease: A longitudinal tensor-based morphometry study in de novo patients without cognitive impairment. Hum Brain Mapp, 35, 3932-3944.

[110] Dickerson BC, Bakkour A, Salat DH, Feczko E, Pacheco J, Greve DN, Grodstein F, Wright CI, Blacker D, Rosas HD, Sperling RA, Atri A, Growdon JH, Hyman BT, Morris JC, Fischl B, \& Buckner RL (2009) The cortical signature of Alzheimer's disease: Regionally specific cortical thinning relates to symptom severity in very mild to mild $\mathrm{AD}$ dementia and is detectable in asymptomatic amyloidpositive individuals. Cereb Cortex, 19, 497-510.

[111] Jubault T, Gagnon JF, Karama S, Ptito A, Lafontaine AL, Evans AC, \& Monchi O (2011) Patterns of cortical thickness and surface area in early Parkinson's disease. Neuroimage, 55, 462-467.

[112] Pagonabarraga J, Corcuera-Solano I, Vives-Gilabert Y, Llebaria G, Garcia-Sanchez C, Pascual-Sedano B, Delfino M, Kulisevsky J, \& Gomez-Anson B (2013) Pattern of regional cortical thinning associated with cognitive deterioration in Parkinson's disease. PLoS One, 8, e54980.

[113] Lyoo CH, Ryu YH, \& Lee MS (2011) Cerebral cortical areas in which thickness correlates with severity of motor deficits of Parkinson's disease. J Neurol, 258, 1871-1876.

[114] Hwang KS, Beyer MK, Green AE, Chung C, Thompson PM, Janvin C, Larsen JP, Aarsland D, \& Apostolova LG (2013) Mapping cortical atrophy in Parkinson's disease patients with dementia. J Parkinsons Dis, 3, 69-76.

[115] Pereira JB, Svenningsson P, Weintraub D, Bronnick K, Lebedev A, Westman E, \& Aarsland D (2014) Initial cog- nitive decline is associated with cortical thinning in early Parkinson disease. Neurology, 82, 2017-2025.

[116] Zhang L, Wang M, Sterling N, Lee E, Eslinger P, Wagner D, Du G, Lewis M, Truong Y, Bowman D, \& Huang $\mathrm{X}$ (2015) Cortical thinning and cognitive impairment in Parkinson's disease without dementia. IEEE/ACM Trans Comput Biol Bioinform PP, 1.

[117] Mak E, Su L, Williams GB, Firbank MJ, Lawson RA, Yarnall AJ, Duncan GW, Owen AM, Khoo TK, Brooks DJ, Rowe JB, Barker RA, Burn DJ, \& O'Brien JT (2015) Baseline and longitudinal grey matter changes in newly diagnosed Parkinson's disease: ICICLE-PD study. Brain, 138, 2974-2986.

[118] Braak H, Del Tredici K, Rub U, de Vos RA, Jansen Steur EN, \& Braak E (2003) Staging of brain pathology related to sporadic Parkinson's disease. Neurobiol Aging, 24, 197211.

[119] Scatton B, Javoy-Agid F, Rouquier L, Dubois B, \& Agid Y (1983) Reduction of cortical dopamine, noradrenaline, serotonin and their metabolites in Parkinson's disease. Brain Res, 275, 321-328.

[120] Fukuda T, Takahashi J, \& Tanaka J (1999) Tyrosine hydroxylase-immunoreactive neurons are decreased in number in the cerebral cortex of Parkinson's disease. $\mathrm{Neu}$ ropathology, 19, 10-13.

[121] Jiang H, He P, Adler CH, Shill H, Beach TG, Li R, \& Shen $\mathrm{Y}$ (2012) Bid signal pathway components are identified in the temporal cortex with Parkinson disease. Neurology, 79, 1767-1773.

[122] Zilles K, Armstrong E, Schleicher A, \& Kretschmann HJ (1988) The human pattern of gyrification in the cerebral cortex. Anat Embryol (Berl), 179, 173-179.

[123] Schaer M, Cuadra MB, Tamarit L, Lazeyras F, Eliez S, \& Thiran JP (2008) A surface-based approach to quantify local cortical gyrification. IEEE Trans Med Imaging, 27, 161-170.

[124] Zhang Y, Zhang J, Xu J, Wu X, Zhang Y, Feng H, Wang J, \& Jiang T (2014) Cortical gyrification reductions and subcortical atrophy in Parkinson's disease. Mov Disord, 29, 122-126.

[125] Malone IB, Leung KK, Clegg S, Barnes J, Whitwell JL, Ashburner J, Fox NC, \& Ridgway GR (2015) Accurate automatic estimation of total intracranial volume: A nuisance variable with less nuisance. Neuroimage, 104, 366-372.

[126] Maltbie E, Bhatt K, Paniagua B, Smith RG, Graves MM, Mosconi MW, Peterson S, White S, Blocher J, El-Sayed M, Hazlett HC, \& Styner MA (2012) Asymmetric bias in user guided segmentations of brain structures. Neuroimage, $\mathbf{5 9}$, 1315-1323.

[127] Scherfler C, Göbel G, Müller C, Nocker M, Wenning GK, Schocke M, Poewe W, \& Seppi K (2016) Diagnostic potential of automated subcortical volume segmentation in atypical parkinsonism. Neurology, 86, 1242-1249.

[128] Braak H, Del Tredici K, Rub U, de Vos RA, Jansen Steur EN, \& Braak E (2003) Staging of brain pathology related to sporadic Parkinson's disease. Neurobiol. Aging, 24, $197-$ 211.

[129] Bullmore E, \& Sporns O (2009) Complex brain networks: Graph theoretical analysis of structural and functional systems. Nat Rev Neurosci, 10, 186-198. 